\title{
Shock-induced fighting as a function of the intensity and duration of the aversive stimulus
}

PAUL I. DREYER ${ }^{1}$ AND RUSSELl CHURCH BROWN UNIVERSITY

Intensity and duration of an aversive stimulus were found to be determinants of the amount of pain-elicited aggression. The probability of fighting was a linear function of $(a)$ the logarithm of the intensity of the shock and (b) the logarithm of the duration of the shock. An increase in the logarithm of the intensity produced approximately twice as great an increase in fighting as an equivalent increase in the duration of the shock.

Ulrich \& Azrin (1962) found that two or more rats in the presence of inescapable shock would assume a stereotyped fighting posture and begin to fight. In that study the number of fights increased with the intensity of shock from $0.5 \mathrm{~mA}$ to $2.0 \mathrm{~mA}$. Higher intensities resulted in fewer fights due to the increasingly debilitating effect of the shock. Azrin, Ulrich, Hutchinson, \& Norman (1964) found that the probability of fighting increased monotonically as a function of the duration of the shock. The present study was designed to replicate the previous findings with regard to intensity and duration and to examine the functional relationships between shock intensity, shock duration, and probability of fighting in a quantitative manner.

Apparatus

The experimental chamber was semicircular in shape (10 in. in diameter and $10.5 \mathrm{in.} \mathrm{high).} \mathrm{The}$ grid floor was made of stainless steel rods $3 / 16$ in. in diameter spaced $9 / 16$ in. apart. Electric shock could be delivered to the floor by means of a Grason-Stadler generator and scrambler (Model E1064GS). The duration, intensity, and frequency of the shocks were regulated by solid state control apparatus.

\section{Subjects and Procedure}

The Ss were male, albino rats (Charles River $C D$ ). They were approximately 200 days old at the time of the experiment and were fed $14 \mathrm{~g}$ of food per day. Three pairs of Ss were used.

On each session two Ss were placed in the experimental chamber and pulses of foot shock of a particular intensity and duration were delivered. On each pulse of shock a fight was recorded if either $S$ stood upright and initiated physical contact with the other $S$ by means of a lunge, bite, or strike. (For each pulse of shock there could be at most one fight.) The dependent variable was the percentage of fights, (No. of fights/No. of shocks) $\times 100$.
A trial consisted of 20 shocks with a 3 sec interval between termination of one shock and onset of the next shock. For the first three sessions the intensity was $1.3 \mathrm{~mA}$, and the duration varied among .05, $.075, .10, .15, .20$, and $.30 \mathrm{sec}$. Each pair of Ss was given 12 trials per session, two under each duration (i.e., 720 shocks, 120 under each condition). The order of treatments was determined by a balanced Latin Square design. This procedure was repeated with the intensity at $2.0 \mathrm{~mA}$ (durations of .05, .075, $.10, .15, .20$, and $.30 \mathrm{sec}$ ), and with the duration at $.05 \mathrm{sec}$ (with intensities of $0.5,0.8,1.0,1.6,2.0$, and $3.0 \mathrm{~mA})$. Finally the duration was fixed at .07 sec and the intensity varied among $1.0,1.3,2.0$, and $3.0 \mathrm{~mA}$. Under this condition 16 trials were given in a single session, two under each intensity (i.e., 320 shocks, 80 under each condition).

\section{Results}

Figure 1 shows the percentage of fights as a function of the logarithm of the duration of shock at 1.3

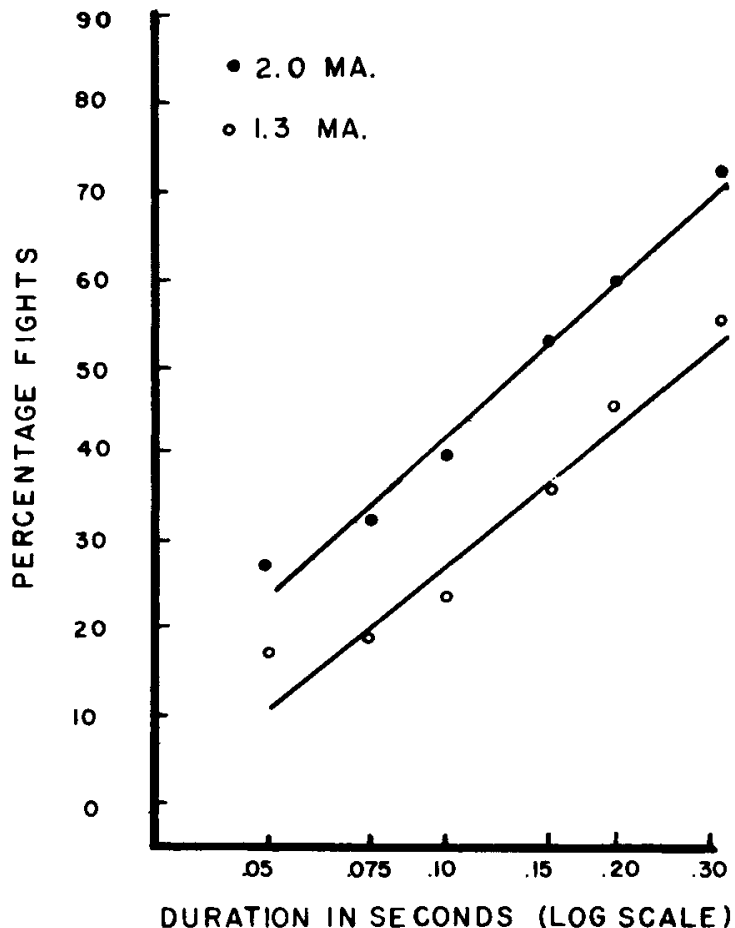

Fig. 1. Percentage of fights as a function of the logarithm of the duration of shock at two intensities. The best-fitting straight lines are $Y=58$ $X+100$ (at $2 \mathrm{~mA}$ ) and $Y=52 X+90$ (at $1.3 \mathrm{~mA}$ ). 


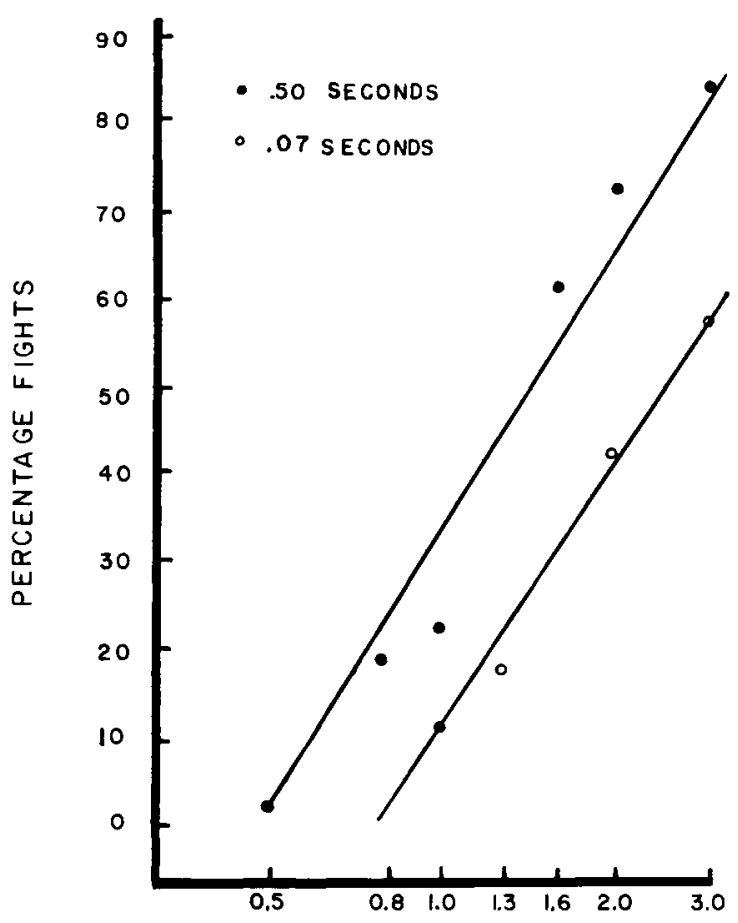

INTENSITY IN MILLIAMPERES (LOG SCALE)

Fig. 2. Percentage of fights as a function of the logarithm of the intensity of shock at two durations. The best-fitting straight lines are $\mathrm{Y}=$ $105 X+33$ (at $0.50 \mathrm{sec}$ ) and $Y=98 X+11$ (at $.07 \mathrm{sec})$.

and $2.0 \mathrm{~mA}$. Figure 2 shows the probability of fighting as a function of the logarithm of shock intensity at .07 and $.50 \mathrm{sec}$. The slopes of both functions in Fig. 1 are approximately 50 while the two slopes in Fig. 2 are approximately 100 . These straight lines produce reasonably close fits to the data points; i.e., the $\mathrm{r}^{2}$ of the percentage of fighting as a function of intensity at .50 sec was .79. The other three $\mathrm{r}^{2} \mathrm{~s}$ were over .90 .

\section{Discussion}

In an experiment on the magnitude of response suppression produced by punishment of various intensities and durations, Church, Raymond, \& Beauchamp (1967) found that the suppression ratio was a linear function of the logarithm of the product of the intensity and duration of the shock. This is analogous to Bloch's Law (Hurvich \& Jameson, 1966) which states that the perception of brightness at very short time intervals is a linear function of the logarithm of the product of intensity and duration of the stimulus. Such a product-rule relationship implies that the dependent variable is a linear function of the logarithm of each independent variable and that the functions generated by each variable are of equal slope. In the present experiment, the percentage of fights was a linear function of both the logarithm of the intensity and the logarithm of the duration of a shock, but the slope of the function for duration was about half of the slope for intensity. These results indicate that the simple product-rule relationship does not apply to shock-induced fighting.

A rough calculation of the intensity and duration slopes from previously published data (Azrin et al, 1964; Ulrich \& Azrin, 1962) also suggests that the intensity slope is greater than that of duration (96 and 31 , respectively). The intensity slope is almost identical with that obtained in the present study, and the lower duration slope is, presumably, a result of the use of values of duration beyond the asymptotic area.

The difference in slope may imply that different mechanisms account for the influence of intensity and of duration on the percentage of fights. For example, the effect of duration may be to increase the probability that the two Ss will be oriented toward each other and thus be in a position to fight. On the other hand, it is possible that rats are more sensitive to an increase in intensity than an increase in duration of a shock. For example, the probability of a "squeak," a vocalization of any type made by $S$ during a shock, was a linear function of the logarithm of the intensity and a linear function of the logarithm of the duration of the shock. Once again the intensity slope was approximately twice as great as the duration slope. (With duration of $.22 \mathrm{sec}$, the intensity slope between .2 and $.8 \mathrm{~mA}$ was approximately 200; with intensity of .6 mA, the duration slope between .04 and .22 sec was approximately 100.) This suggests that the severity of a shock is more affected by a change in intensity than in duration.

\section{References}

AZRIN, N. H., ULRICH, R. E., HUTCHINSON, R. R., \& NORMAN, D. G. Effect of shock duration on shock-induced fighting. $J$. exp. Anal. Behav., 1964, 7, 9-11.

CHURCH, R. M., RAYMOND, G. A., \& BEAUCHAMP, R. D. Response suppression as a function of intensity and duration of a punishment. J. comp. physiol. Psychol., 1967, 63, 39-44.

HURVICH, L. M., \& JAMESON, D. The Perception of Brightness and Darkness. Boston: Allyn and Bacon, Inc., 1966.

ULRICH, R. E., \& AZRIN, N. H. Reflexive fighting in response to aversive stimulation. J. exp. Anal. Behav., 1962, 5, 511-520.

Note

1. National Science Foundation Undergraduate Research Participant. 